\title{
Influence of Race and Neighborhood on the Risk for and Outcomes of Burns in the Elderly in North Carolina
}

\author{
Laura Hendrix, MS, Anthony Charles, MD, MPH, Valorie Buchholz, RN, Samuel Jones, MD, \\ and Bruce Cairns, MD \\ The North Carolina Jaycee Burn Center and the Department of Surgery, University of North \\ Carolina at Chapel Hill
}

\begin{abstract}
Risk factors for mortality and length of hospital stay in elderly burn patients are well established, but the influence of race and socioeconomic status has not been evaluated. This study evaluates the effect of neighborhood level socioeconomic indicators on burn injury risk determines whether race and neighborhood influence burn injury outcomes in the elderly.

Data from the North Carolina Jaycee Burn Center was linked to United States Census Bureau block group socioeconomic data. The odds of death and increased length of hospital stay for Caucasians and Minorities were determined using logistic regression. Rates of burn injury were determined using Poisson regression and multilevel modeling was used to evaluate the influence of neighborhood on outcomes.
\end{abstract}

No significant differences in mortality were observed between Caucasian and Minority patients in individual (Minority OR 0.71; $\mathrm{p}=0.3200)$ and multilevel $(0.72 ; \mathrm{p}=0.4020)$ models. Minorities had significantly higher odds of increased length of hospital stay in individual $(2.05 ; \mathrm{p}=0.0020)$ and multilevel $(2.55 ; 0.037)$ models. High proportions of rural households $(R R=1.39 ; \mathrm{p}=0.0010)$ and poverty $(1.26 ; \mathrm{p}<0.0001)$ were significantly associated with increased risk of burn injury. Additional investigation using larger databases will allow further elucidation of the contextual effects of socioeconomic status on burn injury in the elderly.

\section{INTRODUCTION}

Older adults are at high risk for burn injury [1], [2], and [3] and experience significant burnrelated morbidity and mortality [4]. Burns and other fire-related injuries are currently the second-leading cause of death from home accidents among older adults [5]. Extremes of age are an independent predictor of mortality in burn injury. In the elderly cohort this is due in part, to pre-existing comorbidities complicating surgical management [6].

Individual-level risk factors for mortality and increased hospital length of stay (LOS) in burn patients of all ages are well established. Along with advanced age, percent of total body

\footnotetext{
(c) 2011 Elsevier Ltd and ISBI. All rights reserved.

Laura Hendrix MS, Clinical Trials Consortium, Department of Surgery, 4024 Burnett-Womack, CB 7211, University of North Carolina at Chapel Hill, Chapel Hill, NC 27599.

CONFLICT OF INTEREST STATEMENT The authors have no financial and personal relationships with others people or organization that could inappropriately influence their work.

Publisher's Disclaimer: This is a PDF file of an unedited manuscript that has been accepted for publication. As a service to our customers we are providing this early version of the manuscript. The manuscript will undergo copyediting, typesetting, and review of the resulting proof before it is published in its final citable form. Please note that during the production process errors may be discovered which could affect the content, and all legal disclaimers that apply to the journal pertain.
} 
surface area burned (\%TBSA), comorbid conditions and inhalation injury are the major independent contributors to mortality in the elderly. Risk factors for increased length of hospital stay (LOS) in elderly burn patients include \%TBSA, inhalation injury, flame injury, and comorbid conditions such as diabetes and cardiovascular disease [7] and [8]. The geriatric sequelae that may predispose the elderly to increased burn injury include decreased physical strength, impaired protective mechanisms, hearing impairment, and poor vision [9]. Older adults may have limited mobility or slower reaction time making escaping house fires difficult [10].

There are also socioeconomic determinants of burn injury in the elderly, particularly since $20 \%$ of the elderly in the United States live below the poverty line [11]. Older adults are less likely to have a functional smoke detector in their home [12]. Additionally, they may live in older houses or be unable to maintain houses sufficiently to reduce the possibility of fire. Hence, older adults are more likely to have more extensive TBSA burn injuries, inhalation injury, and respiratory failure as compared to their younger counterparts [6]. The influence of race and socioeconomic status on these outcomes and on the risk of burn injury requires further investigation.

Health outcome and access disparities among minorities and the economically deprived in the United States are well recognized and manifested in a wide range of indicators including burn injury [13] and [14]. In 2006, the age-adjusted all-cause mortality rate for African Americans was 30\% higher than the rate for Caucasians [14]. Compared to the Caucasian population, African Americans have an elevated death rate for eight of the ten leading causes of death [15]. Age-adjusted all-cause mortality rates in African Americans was one and a half times that of whites in 1998, the same as what it was in 1950 [15]. These inequalities may be explained, at least in part, by socioeconomic status [16]. While the relationship between race and socioeconomic status is complex, they are highly interrelated and both are strongly associated with health and mortality [17].

Area-based socioeconomic indicators provide a means of characterizing an area's residents, as well as evaluating the contextual effect of characteristics not reducible to the individual level, such as proportion of residents living in poverty. The availability of multiple area level indicators from the US Census bureau and the development of geocoding tools have allowed evaluation of the effects of area level social inequality on health outcomes. Numerous studies have shown that living in a deprived neighborhood exerts an effect on the health of residents above and beyond their own economic status [18] and[19].

One of the key tenets of injury prevention is to identify high-risk cohorts and environments so that targeted prevention strategies can be deployed. Geographic information systems (GIS) have become important tools for understanding population health. GIS allows the integration of data from a variety of sources and provides a means of analyzing spatial distribution and patterns. A growing body of literature has demonstrated that characteristics of communities where people live, such as family stability, housing conditions, income and wealth, crime, and unemployment influence health outcomes [20] and [21]. The use of GIS enables linkage of individual data and community level data obtained from the United States Census Bureau, facilitating the analysis of the geographic dimensions of health at a variety of levels; from state to county to the smallest unit of analysis, the census block group, consisting of a few city blocks.

The aim of this study is to identify demographic and geographic subgroups at increased burn injury risk, and to examine socioeconomic, individual, and neighborhood-level determinants of burn injury and outcome among the elderly population admitted to the UNC Jaycee Burn Center (JBC) between 2000 and 2008. 


\section{METHODS}

After approval from the UNC IRB, demographic and clinical data was obtained from the JBC registry for patients aged 60 and older admitted between January 2000 and December 2008. Data from patients residing outside of North Carolina were excluded from the analysis.

\section{Individual-level analysis}

Patient clinical data was obtained from the JBC registry in an Excel spreadsheet and imported into Stata 10 (Statacorp, College Station, TX) for analysis. Patient variables available from the registry included \%TBSA, age, gender, race, presence of inhalation injuries, patient insurance, hospital length of stay, and whether patient survived, and if so, hospital dispensation. The presence of any comorbidity utilized in the calculation of the Charlson comorbidity score (diabetes, peripheral vascular disease, congestive heart failure, HIV infection, etc), a predictor of long-term survival, was also available.

Because of non-normal distribution of data, patient age was stratified into quartiles, as was \% TBSA. Due to small numbers of patients of race other than Caucasian and African American, race was re-categorized as Caucasian or Minority. LOS was dichotomized at its median as it also exhibited non-normal distribution.

Baseline characteristics of Caucasian and Minority patients were compared using t-tests for continuous data and chi-squared tests for categorical data. Univariate analysis was carried out to evaluate the odds of mortality and LOS>median value. Variables found to be significantly associated with these outcomes were modeled in multivariate logistic regression analyses. Likelihood ratio tests were carried out to assess the linearity of effect for categorical variables.

\section{Block group-level analysis}

Block group and county boundary shapefiles were obtained from the North Carolina Center for Geographic Information and Analysis (http://www.cgia.state.nc.us). The census block is the smallest geographic unit for which 100 percent data is collected by the United States Census Bureau, and approximates a city block. The block group, a subdivision of the census tract, contains approximately 39 block groups, and is the smallest geographic unit for which 1-in-6 sample data is collected. Block groups typically contain between 300 and 3,000 people. Block group and county boundaries were projected in ArcView 9.3 (ESRI, Redmond, CA). The catchment area from which the JBC draws patients was defined as all block groups within counties east of Forsyth, Stokes, and Davidson county boundaries as well as the Charlotte metropolitan area. This area comprises approximately two-thirds of the state.

The latitude and longitude of each patient's address was determined using Excel Geocoding Tool v2 (Juice Analytics, Reston, VA). Each patient's location was then projected into its respective block group in ArcView. For purposes of the analysis, patients residing within North Carolina but outside the JBC catchment area were excluded. Summary counts of patients in each block group were generated from this data.

Block group attribute data from 2000 was obtained from the US Census Bureau. Race, age, sex, and housing characteristics were obtained from Summary File 1, which provides 100\% data for every person and housing unit in the United States. Education, median household income, and poverty status data were obtained from Summary File 3, a 1-in-6 sample weighted to represent the total population. This data was merged with the block group shapefile based on unique 12-digit block group codes. 
Finally, patient count data was merged with block group socioeconomic data to create a complete database containing the socioeconomic attributes of, and number of patients admitted from, each block group. This data was then imported into Stata 10 for analysis.

Continuous variables were categorized either by their quartile distributions or by a priori considerations, for example the federal definition of "poverty area" as regions where $\geq 20 \%$ of the population is below the US poverty line [22]. Block groups were considered to be rural if the proportion of rural households was greater than the median value for all block groups. The characteristics of census blocks in which burn injuries occurred were compared to those in which no burn injury occurred using the Wilcoxon rank sum or chi-squared tests where appropriate.

For this portion of the analysis, the data were counts of burn injuries nested within block groups, standardized by block group population size. This data approximated a Poisson distribution, with a large number of trials and a small probability of success. Uni- and multivariate Poisson regression was therefore used to model the effects of block group level socioeconomic indicators on the risk of burn injury. The assumption of independence of observations in this analysis may have been violated due to multiple observations from the same block group. To adjust for any such clustering effect, rate ratios, p-values, and $95 \%$ confidence intervals were calculated using a random effects model. Likelihood ratio tests were carried out to evaluate the significance of clustering effects.

\section{Multilevel analysis}

In order to adjust individual level predictors for correlation between individuals within block groups, multilevel logistic regression modeling was carried out using individual variables as the first level and block group as the second level of the model. Race and other variables found to be significantly associated with mortality and LOS>median in the multivariate logistic regression models were included in the multilevel models. Likelihood ratio tests were carried out to evaluate the significance of block group effects observed at the individual level and assess whether multilevel or multivariate logistic regression models provided the best fit of the data.

\section{RESULTS}

\section{Individual-level analysis}

Between 2000 and 2008, a total of 476 patients aged 60 and older from North Carolina were admitted to the burn center. Of these, there were 406 patients resident within the JBC catchment whose addresses could be successfully geocoded and linked to census data. The characteristics of those excluded from the analysis were not significantly different from those who were included.

The characteristics of this population are shown in Table $1.36 .2 \%$ of patients were female and $63.8 \%$ were male. The overall median age was 69.8 years. $277(68.2 \%)$ of patients were of white ethnicity and $129(31.7 \%)$ were of other ethnicity. Approximately three quarters of patients had burn injuries of $<18 \%$ TBSA (73.1\%), and 93 (22.9\%) patients died. Median hospital length of stay (LOS) for all patients was 10 days, with Minorities having significantly longer median LOS (15 days) compared to Caucasians ( 7 days; $\mathrm{p}=0.0006$ ). 66 (16.2\%) patients had inhalation injuries. There were significantly more Minority patients with diabetes $(\mathrm{p}=0.0004)$ and peripheral vascular disease $(\mathrm{p}=0.0390) .28$ patients died within 24 hours of admission. The majority of these had non-survivable burns, serious comorbidities, or both; median TBSA for patients who died $\leq 24$ hours after admission was $62.5 \%$ (data not shown). 
The odds of mortality and LOS>median were evaluated in a univariate analysis (Table 2). Minorities had $15 \%$ lower odds of mortality than Caucasians but this association was not significant $(\mathrm{OR}=0.85 ; 95 \% \mathrm{CI}=0.81-1.41 ; \mathrm{p}=0.5184)$. Mortality was significantly associated with male gender $(1.63 ; 1.01-2.62 ; \mathrm{p}=0.0410)$, highest age quartile $(2.81 ; 1.47-5.36$; $\mathrm{p}=0.0015)$, highest TBSA quartile $(21.08 ; 6.98-63.64 ; \mathrm{p}<0.0001)$, male sex $(1.63 ; 1.01-2.62$; $\mathrm{p}=0.0410)$, inhalation injury $(4.30 ; 2.41-7.68 ; \mathrm{p}<0.0001)$, and diabetes $(0.51 ; 0.26-1.00$; 0.0352). After adjusting for age, TBSA, and inhalation injury in the multivariate analysis, Minorities had 29\% lower odds of mortality than Caucasians, but the association remained non-significant $(0.71 ; 0.36-1.39 ; \mathrm{p}=0.3200)$. Age quartile remained significantly associated with death and demonstrated a linear effect $(1.66 ; 1.26-2.18 ; \mathrm{p}<0.0001)$. TBSA in the third $(2.87 ; 1.03-8.05 ; \mathrm{p}=0.0440)$ or fourth $(22.86 ; 8.75-59.70 ; \mathrm{p}<0.0001)$ quartile and inhalation injury $(3.07 ; 1.56-6.08 ; \mathrm{p}=0.001)$ remained significantly associated with mortality.

In the univariate analysis, Minorities had twice the odds of LOS $>$ median compared to Caucasians $(2.01 ; 1.31-3.11 ; \mathrm{p}=0.0012)$. TBSA in the third $(2.60 ; 1.40-4.81 ; \mathrm{p}=0.0016)$ or fourth $(1.92 ; 1.07-3.43 ; \mathrm{p}=0.0250)$ quartile, peripheral vascular disease (PVD) (3.55; $1.38-9.13 ; \mathrm{p}=0.0050)$, and other comorbidities $(2.72 ; 1.22-6.09 ; \mathrm{p}=0.0109)$ were also associated with LOS>median. After adjustment for TBSA and PVD in the multivariate model, Minority race remained significantly associated with LOS >median, $(2.05 ; 1.31-3.21$; $\mathrm{p}=0.0020)$. TBSA in the third $(2.93 ; 1.58-5.42 ; \mathrm{p}=0.0010)$ and fourth $(2.13 ; 1.18-3.84$; $0.0120)$ quartile and peripheral vascular disease $(3.40 ; 1.29-8.95 ; \mathrm{p}=0.0130)$ also remained significantly associated with LOS $>$ median in the multivariate model.

\section{Census-block level analysis}

The state of North Carolina consists of 5251 inhabited block groups. 3631 block groups are located within the JBC catchment area. The 406 patients in this analysis resided in 377 block groups within this area. Block groups in which burn injury occurred had significantly lower median household income $(\mathrm{p}=0.0009)$, proportion of college or postgraduate graduates $(\mathrm{p}=0.0015)$; and proportion of Caucasian residents $(\mathrm{p}=0.0001)$ (Table 3$)$ than those in which no burn injury occurred. Block groups which burn injury occurred also had significantly higher proportion of the population living below the poverty line $(\mathrm{p}<0.0001)$, in areas classified as rural $(\mathrm{p}<0.0001)$, and single female household heads $(\mathrm{p}=0.0003)$. No significant difference in the proportions of rental households was observed $(\mathrm{p}=0.5681)$.

Variables that were significantly associated with reduced risk of burn injury in the univariate analysis were median household income $(0.76 ; 0.64-0.90 ; \mathrm{p}=0.001)$, proportion of population with college or postgraduate educational attainment $(0.75 ; 0.63-0.90 ; \mathrm{p}=0.001)$, and proportion Caucasian $(0.71 ; 0.58-0.83 ; \mathrm{p}<0.001)$ (Table 4$)$. Variables significantly associated with increased risk of burn injury were proportion living below the poverty line $(1.39 ; 1.18-1.63 ; \mathrm{p}=0.001)$, proportion of single female household heads $(1.24 ; 1.05-1.47$; $\mathrm{p}=0.010)$ and proportion aged 60 or older $(1.23 ; 1.05-1.47 ; \mathrm{p}=0.013)$. The proportion of rental households was not significantly associated with risk of burn injury (1.09; 0.92-1.30; $\mathrm{p}=0.327)$, nor was proportion of rural households $(1.39 ; 0.98-1.99 ; \mathrm{p}=0.068)$. In the multivariate analysis, only proportion living below the poverty line $(1.26 ; 1.16-1.39$; $\mathrm{p}<0.001$ ) was significantly associated with risk of burn injury, with being considered a rural census block demonstrating borderline significance $(1.42 ; 1.00-2.02 ; \mathrm{p}=0.050)$. Likelihood ratio tests indicated that all variables demonstrated significant block group clustering effects (data not shown). Significant correlations were observed between all socioeconomic variables (Spearman's correlation coefficient $\mathrm{p}<0.05$ ) with the exception of both median household income and proportion living in poverty with proportion of rural households (data not shown). 


\section{Multilevel analysis}

After adjusting for area effects, estimates for individual risk factors became less precise than the single level estimates. The odds of mortality for each age quartile increased to 1.83 (1.02-3.29; $\mathrm{p}=0.043)$, and for the highest TBSA quartile to 40.33 (1.76-922.47; $\mathrm{p}=0.021)$ (Table 5). For inhalation injury, the odds of mortality were no longer significant (4.08; 0.97-17.19; $\mathrm{p}=0.056)$. The odds of LOS $>$ median increased to $2.55(1.06-6.18 ; \mathrm{p}=0.037)$ for Minority race. The odds of LOS>median for PVD was increased to 4.64 (1.00-21.50; $\mathrm{p}=0.050$ ) and was no longer significant, while only the third quartile of TBSA remained significant, increasing to $3.95(1.19-13.11 ; \mathrm{p}=0.025)$. Likelihood ratio tests indicated some area effects but these were not significant for mortality $(\mathrm{p}=0.3175)$ or LOS $>$ median $(\mathrm{p}=0.1982)$, indicating that the multiple logistic regression models were a better fit to both mortality and LOS data than the multilevel models.

\section{DISCUSSION}

As the elderly population in the United States grows, the number of burn hospitalizations within this cohort is likely to increase. However, the burn injury burden is not shared equally among this subpopulation, with those in lower socioeconomic groups experiencing a disproportionate burden of injury morbidity and mortality [23]. In this study, there were no significant differences between Caucasian and Minority burn patients with respect to mortality in any of the models utilized. Minority race, however, was highly associated with increased LOS, with more than twice the odds of LOS $>$ median as compared to Caucasians in the individual level analysis, and two and a half times the odds of LOS>median than Caucasians after adjusting for area level effects. This finding is consistent with previous studies that have found that Minorities experience longer hospitalizations than do Caucasians [24]. Anecdotal evidence at our facility suggests that Minority patients remain hospitalized for longer periods after burn injuries because of challenges in obtaining support outside the hospital for complex post-discharge burn care needs. Whether the increased LOS experienced by Minorities can actually be attributed to race, or whether this phenomenon is a result of the interplay of race and socioeconomic status, remains to be determined. This study indicates that neighborhood exerts a contextual effect on LOS that modifies individual-level risk factors.

Adjustment for neighborhood level socioeconomic status in the multilevel model did not change the odds of mortality for Minorities substantially, but increased the odds of increased length of hospital stay by $50 \%$. Likelihood ratio test results indicated that area level effects in these models were not significant, and that logistic regression models provided the best fit to the data. Multilevel models, however, may not be reliable when there are few groups or if many groups contain only one observation, as is the case in this study, with only 26 block groups having two or more observations. A larger sample size with multiple observations within each block group would provide a more robust estimate of the group effects on mortality and LOS. Further investigation using national burn data or additional age groups within the JBC catchment area will provide more robust estimates of the effect of socioeconomic status.

Among the socioeconomic status indicators utilized, poverty and rural location appear to have the strongest contextual influence on the risk of burn injury in the elderly. The federal definition of poverty is based on income levels relative to cost of providing food and other basic living requirements. Income-based poverty is highly correlated with other socioeconomic indicators, as observed in our analysis. Whether poverty mediates the effects of other socioeconomic indicators or is a direct influence on the risk of burn injury in the elderly remains to be determined. 
Rural populations have been shown to have disproportionately high injury mortality rates, and decreasing population density is the strongest predictor of county-specific trauma death rates in the United States [25]. 73\% of rural home fires occur in homes without operational smoke detectors [26]. In the United States, the percentage of homes that experience a fire and have a working smoke alarm is $41.8 \%$ in urban areas but only $20.8 \%$ in rural areas [27]. The isolation of rural homes may also cause delayed detection and longer response times on the part of fire and emergency service personnel.

Age and tenure of housing have been shown to partially mediate the association between risk of burn injury and poverty [28]. Older houses are less likely to be in compliance with housing, building, or sanitary codes and have substandard electrical and heating systems, narrow stairwells or other safety hazards [29]. Inadequate maintenance is a common problem in rental properties in low-income areas. Elderly homeowners may also be unable to maintain homes adequately. This study found that areas with up to a quarter of rental homes had higher risk of burn injury, but in areas with a higher proportion of rental homes this association was not significant.

Significant correlation was observed between all the socioeconomic indicator variables used in this analysis. Determining the causal pathways by which individual socioeconomic indicators lead to burn injury and isolating the effects of individual indicators will thus be challenging. The use of a composite deprivation index such as the Townsend index, which incorporates highly correlated area based measures [30], may be useful to reflect a single measure of area socioeconomic status. These indices, however, have drawbacks. They are difficult to construct and validate [18], omit potentially important contributions of unmeasured or unknown indicators, and mask the underlying contributions of separate indicators.

Taken together, a picture emerges in which the most deprived populations of elderly people are those most at risk for burns. The complexities of race, socioeconomic status and the correlations between them make it difficult to isolate the contributions of each indicator to the risk of burn, and indeed any health-related problem, particularly when area level rather than individual level socioeconomic data is examined.

Injury prevention efforts in the past 50 years have attempted to reduce historically existing racial and ethnic disparities in residential fire, poisonings, pedestrian injury, motor vehicle traffic, suffocation, homicide, and others [31]. Some successes have been achieved [32], [33], [34], [35], [36], [37], and [38] however; the application of knowledge, access to safety devices, changes in behavior and achieved rates of safety practice may be lower in resourcelimited communities [39]. This is highly relevant to older adults, as $20 \%$ of the elderly in the United States live below the poverty line [11].

This study is to our knowledge unique in the field of burn injury research and represents an important step toward understanding how disadvantages, measured for both people and places, can operate to increase risk and mortality from burn injury. The findings presented here provide evidence for the influence of area level socioeconomic indicators on the risk of burn, mortality, and increased LOS in the elderly in the JBC catchment area.

Further research is warranted. A larger sample size would allow more precise estimates of the risk factors for burn injury and associated mortality and hospital LOS. The use of larger regional or national databases would enable the study of a much larger population, as well as an analysis of larger geographic trends in burn injury in the elderly. Second, more clearly refining socioeconomic risk factors for these outcomes by obtaining individual-level socioeconomic status information from patients would allow analysis of these risk factors at the individual level. While area-level socioeconomic indicators provide a proxy for 
individual status, they cannot be applied to the individual. The collection of socioeconomic data from patients would, however, require the commitment of considerable resources.

The increasing size and lifespan of the elderly population in the United States places an increasing burden on its health care system. The treatment and rehabilitation of burn patients requires significant resources. Burn injuries represent $1 \%$ of the incidence of injuries and $2 \%$ of the total costs of injuries in the United States, approximately $\$ 7.5$ billion per year [40]. Elderly patients, particularly those with comorbid conditions, require more resources than their younger counterparts. A reduction in the incidence of burn injury in this age group would result in significant cost savings. Identification of areas with a population most at risk for burn injury is essential for the development of effective prevention programs in an era of limited resources. This study provides a first look at the risk factors for and outcomes for burn injury in the elderly in North Carolina at both the individual and community level.

\section{Acknowledgments}

This research was supported by the Center for Aging and Diversity at the UNC Institute on Aging at the University of North Carolina. The study sponsors had no involvement in the study design, data collection, analysis and interpretation of data, writing of the manuscript, or decision to submit the manuscript for publication.

\section{References}

1. Barillo DJ, Goode R. Fire-fatality study: demographics of fire victims. Burns. 1996; 22(2):85-8. [PubMed: 8634135]

2. Ehrlich AR, Kathpalia S, Boyarsky Y, et al. Elderly patients discharged home from the emergency department with minor burns. Burns. 2005; 31(6):717-20. [PubMed: 16039785]

3. Tejerina C, Reig A, Codina J. Burns in patients over 60 years old: epidemiology and mortality. Burns. 1992; 18(2):149-52. [PubMed: 1590932]

4. Lionelli GT, Pickus EJ, Beckum OK, et al. A three decade analysis of factors affecting burn mortality in the elderly. Burns. 2005; 31(8):958-63. [PubMed: 16269217]

5. Ehrlich AR. Preventing burns in older patients. Am Fam Physician. 2006; 74(10):1692-93.

6. Bessey PQ, Arons RR, Dimaggio CJ, Yurt RW. The vulnerabilities of age: burns in children and older adults. Surgery. 2006; 140(4):705-15. [PubMed: 17011919]

7. Lumenta D, Hautier A, Desouches C, Gouvernet J, Giorgi R, Manelli J, et al. Mortality and morbidity among elderly people with burns - evaluation of data on admission. Burns. 2008; 34(7): 965-74. [PubMed: 18378400]

8. Burton K, Sharma V, Harrop R, Lindsay R. A population-based study of the epidemiology of acute adult burn injuries in the Calgary Health Region and factors associated with mortality and hospital length of stay from 1995 to 2004. Burns. 2009; 35(4):572-9. [PubMed: 19203840]

9. Mahar P, Wasiak J, Bailey M, Cleland H. Clinical factors affecting mortality in elderly burn patients admitted to a burns service. Burns. 2008; 34(5):629-36. [PubMed: 18207331]

10. Tan J, Banez C, Cheung Y, Gomez M, Nguyen H, Banfield J, et al. Effectiveness of a burn prevention campaign for older adults. J Burn Care Rehabil. 2004; 25(5):445-51. [PubMed: 15353939]

11. American Association of Retired People; 2010 April. Older Americans in Poverty: A snapshot [document on the Internet]. [cited 2010 August 02]. Available from: http://www.aarp.org/work/retirement-planning/info-04-2010/2010-03-poverty-new.html

12. Erhlich AR, Bak RY, Wald-Cagan P, Greenberg DF. Risk factors for fires and burns in homebound, urban elderly. J Burn Care Res. 2008; 29(6):985-7. [PubMed: 18849831]

13. Ferraro KF, Thorpe RJ, McCabe GP, Kelley-Moore JA, Jiang Z. The color of hospitalization over the adult life course: cumulative disadvantage in black and white? J Gerontol B Psychol Sci Soc Sci. 2006; 61(6):S299-306. [PubMed: 17114309]

14. Edelman L. Social and economic factors associated with the risk of burn injury. Burns. 2007; 33(8):958-65. [PubMed: 17869003] 
15. Williams D, Collins C. Racial residential segregation: a fundamental cause of racial disparities in health. Public Health Rep. 2001; 116(5):404-16. [PubMed: 12042604]

16. Farmer MM, Ferraro KF. Are racial disparities in health conditional on socioeconomic status? Soc Sci Med. 2004 April 26; 60(1):191-204. [PubMed: 15482878]

17. Williams DR, Lavizzo-Mourep R, Warren RC. The concept of race and health status in America. Public Health Rep. 1994; 109(1):26-41. [PubMed: 8303011]

18. Pickett K, Pearl M. Multilevel analyses of neighbourhood socioeconomic context and health outcomes: a critical review. J Epidemiology Community Health. 2001; 55(2):111-22.

19. Riva M, Gauvin L, Barnett TA. Toward the next generation of research into small area effects on health: a synthesis of multilevel investigations published since July 1998. J Epidemiology Community Health. 2007; 61(10):853-61.

20. LeClere FB, Rogers RG, Peters KD. Ethnicity and mortality in the United States: individual and community correlates. Social Forces. 1997; 76(n1):169-98.

21. Robert SA. Community-level socioeconomic status effects on adult health. J Health Soc Behav. 1998; 39(1):18-37. [PubMed: 9575702]

22. US Census Bureau; 2002 September 05. Poverty areas [document on the Internet]. [cited 2010 August 04]. Available from: http://www.census.gov/population/socdemo/statbriefs/povarea.html

23. Park JO, Shin SD, Kim JK, Song KJ, Peck MD. Association between socioeconomic status and burn injury severity. Burns. 2009; 35(4):482-90. [PubMed: 19216029]

24. Ferraro K, Thorpe R, McCabe G, Kelley-Moore J, Jiang Z. The color of hospitalization over the adult life course: cumulative disadvantage in black and white? J Gerontol. 2006; 61(6):s299-306.

25. Rutledge R, Fakhry SM, Baker CC, et al. A population-based study of the association of medical manpower with county trauma death rates in the United States. Ann Surg. 1994; 219(5):547-67. [PubMed: 8185404]

26. The Rural Fire Problem in the United States. Washington, DC: Federal Emergency Management Agency, United States Fire Administration; 1997.

27. McGwin G, Chapman V, Rouseculp M, Robison J, Fine P. The epidemiology of fire-related deaths in Alabama, 1992-1997. J Burn Care Rehabil. 2000; 21(1 Pt 1):75-83. [PubMed: 10661543]

28. Shenassa E, Stubbendick A, Brown MJ. Social disparities in housing and related pediatric injury: a multilevel study. Am J Pub Health. 2004; 94(4):633-39. [PubMed: 15054017]

29. Runyan C, Bangdiwala S, Linzer M, Sacks J. Risk factors for fatal residential fires. N Engl J Med. 1992; 327(12):859-63. [PubMed: 1508246]

30. Morris R, Carstairs V. Which deprivation? A comparison of selected deprivation indexes. J Public Health Med. 1991; 13(4):318-26. [PubMed: 1764290]

31. US Department of Health and Human Services. Healthy People 2010. Vol. II. McLean, VA: International Medical Publishing; 2000.

32. Bonnie, RJ.; Fulco, CE.; Liverman, CT., editors. Institute of Medicine. Reducing the Burden of Injury: Advancing Prevention and Treatment. Washington, DC: National Academy Press; 1999. p. 85-6.

33. US Preventive Services Task Force. Guide to Clinical Preventive Services, Report of the U.S Preventive Services Task Force. 2. Philadelphia, PA: Lippincott Williams \& Wilkins; 1996.

34. Davidson LL, Durkin MS, Kuhn L, O’Connor P, Barlow B, Heagarty MC. The impact of the Safe Kids/Healthy Neighborhoods Injury Prevention Program in Harlem, 1988 through 1991. Am J Public Health. 1994; 84(4):580-6. [PubMed: 8154560]

35. Daniels F, Moore W, Conti C, et al. The role of the African American physician in reducing traffic-related injury and death among African Americans: consensus report of the National Medical Association. J Natl Med Assoc. 2002; 94(2):108-18. [PubMed: 11858225]

36. Quayle KS, Wick NA, Gnauck KA, Schootman M, Jaffe DM. Description of Missouri children who suffer from burn injuries. Inj Prev. 2000; 6:255-8. [PubMed: 11144622]

37. Pressley JC, Barlow BA. Childhood and adolescent injury due to falls from buildings and structures. Inj Prev. 2005; 11(5):267-73. [PubMed: 16203834]

38. Federal Emergency Management Agency. Fire in the United States: 1983-1990. Emmitsburg, MD: US Fire Administration; 1993. Publication USFA/FA140 
39. Pressley J, Barlow B, Kendig T, Paneth-Pollack R. Twenty-year trends in fatal injuries to very young children: the persistence of racial disparities. Pediatrics. 2007; 119(4):875-84.

40. Centers for Disease Control and Prevention; 2009 October 02. Fire deaths and injuries: fact sheet [document on the internet]. [cited 2010 August 05]. Available from:

http://www.cdc.gov/HomeandRecreationalSafety/Fire-Prevention/fires-factsheet.html 


\section{Table 1}

Characteristics of patients aged 60 or older admitted to North Carolina Jaycee Burn Center from 2000 to 2008 , by race

\begin{tabular}{|c|c|c|c|c|}
\hline & All patients $(\%)(n=406)$ & Caucasian (\%) $n=277$ & Minority (\%) n=129 & p-value \\
\hline \multicolumn{5}{|l|}{ Sex } \\
\hline Male & $259(63.8)$ & $184(66.6)$ & $75(58.1)$ & \\
\hline Female & $147(36.2)$ & $93(33.5)$ & $54(41.9)$ & 0.1058 \\
\hline \multicolumn{5}{|l|}{ Age Quartile } \\
\hline $60-63.5 \mathrm{yrs}$ & $101(24.9)$ & $72(26.0)$ & $29(22.5)$ & \\
\hline 63.6-69.7 yrs & $101(24.9)$ & $56(20.2)$ & $45(34.9)$ & \\
\hline 69.8-76.9 yrs & $101(24.9)$ & $75(27.1)$ & $26(20.2)$ & \\
\hline 77-99.2 yrs & $103(25.4)$ & $74(26.7)$ & $29(22.5)$ & 0.3834 \\
\hline \multicolumn{5}{|l|}{ TBSA\% quartile } \\
\hline $0-3 \%$ & $89(22.5)$ & $60(22.4)$ & $29(22.8)$ & \\
\hline $4-8 \%$ & $106(26.8)$ & $66(24.6)$ & $40(31.5)$ & \\
\hline $9-17 \%$ & $94(23.8)$ & $70(26.1)$ & $24(18.9)$ & \\
\hline $18-100 \%$ & $106(26.8)$ & $72(26.9)$ & $34(26.8)$ & 0.6252 \\
\hline Inhalation injury & $66(16.2)$ & $39(14.1)$ & $27(20.9)$ & 0.0815 \\
\hline Median LOS (range) & $10(1-351)$ & $7(1-351)$ & $15(1-199)$ & 0.0006 \\
\hline \multicolumn{5}{|l|}{ Comorbidities } \\
\hline Diabetes & 89 (21.9) & $47(17.0)$ & $42(32.6)$ & 0.0004 \\
\hline Peripheral vascular disease & $26(6.4)$ & $13(4.69)$ & $13(10.1)$ & 0.0390 \\
\hline Cerebral vascular event & $4(1.0)$ & $3(1.1)$ & $1(0.8)$ & 0.7700 \\
\hline Other & $32(7.9)$ & $23(8.3)$ & $9(7.0)$ & 0.6442 \\
\hline Congestive heart failure & $29(7.1)$ & $21(7.6)$ & $8(6.2)$ & 0.6153 \\
\hline Death & $93(22.9)$ & $66(23.8)$ & $27(20.9)$ & 0.5180 \\
\hline
\end{tabular}




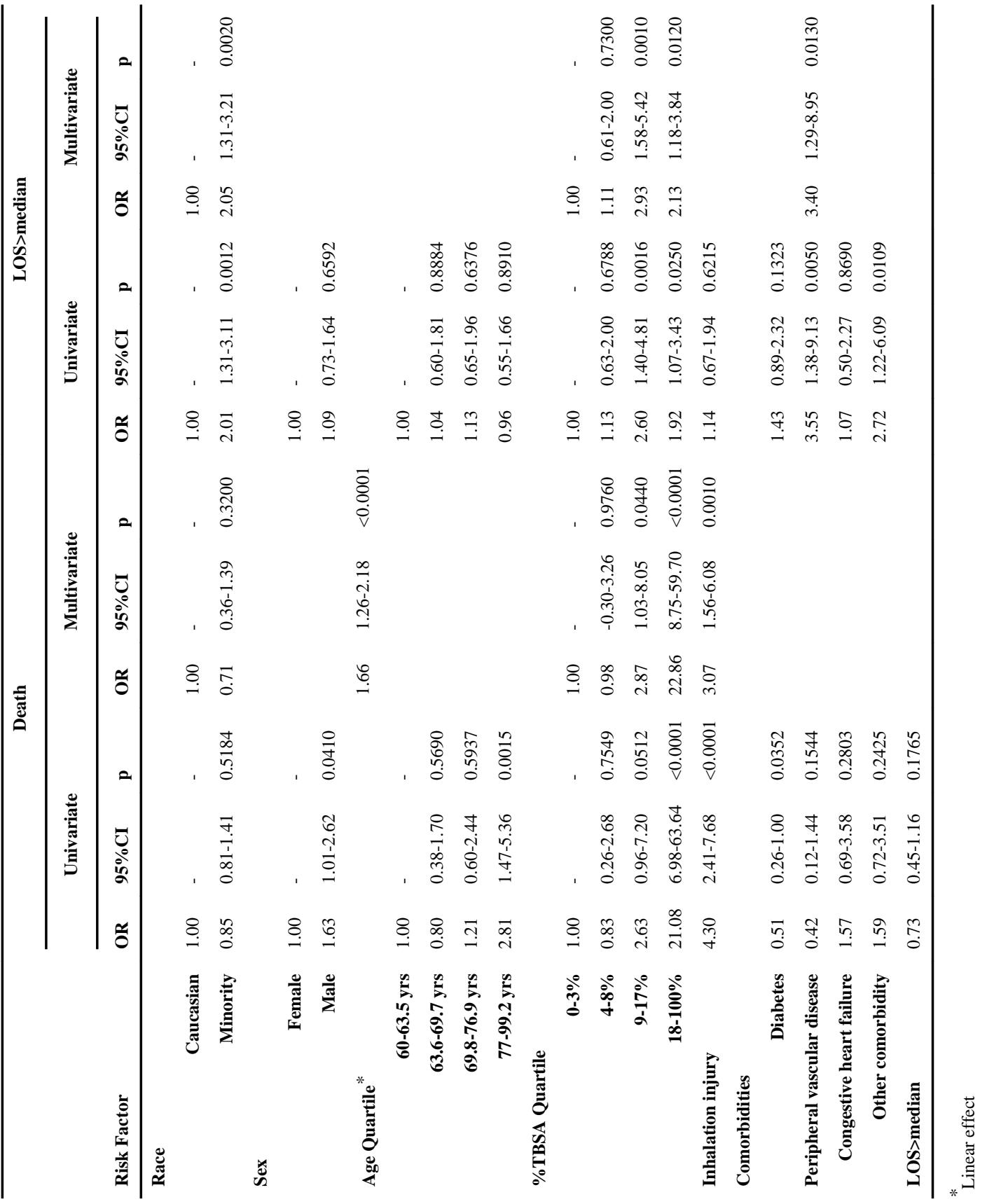


Table 3

Socioeconomic attributes of catchment area census block groups (CBG), 2000 United States Census ${ }^{\S}$

\begin{tabular}{llll}
\hline Risk factor & CBG without burn injuries (n=3631) & CBG with burn injuries (n=377) & p-value $^{*}$ \\
\hline Median household income, USD & 36,209 & 33854 & 0.0009 \\
Rural census block & 48.8 & 60.2 & $>0.0001^{* *}$ \\
Proportion with college/postgraduate degree & 17.4 & 15.4 & 0.0015 \\
Proportion Caucasian residents & 72.1 & 64.8 & 0.0001 \\
Proportion rental households & 25.7 & 25.6 & 0.5681 \\
Proportion below federal poverty line & 11.7 & 14.11 & $<0.0001$ \\
Proportion single female household head & 10.0 & 11.2 & 0.0003 \\
Proportion >59 years old & 21.3 & 21.2 & 0.3975 \\
\hline
\end{tabular}

$\S_{\text {Median values except rural census block }}$

*Wilcoxon rank sum test

*** Chi-squared test 
10
응
$\frac{0}{10}$

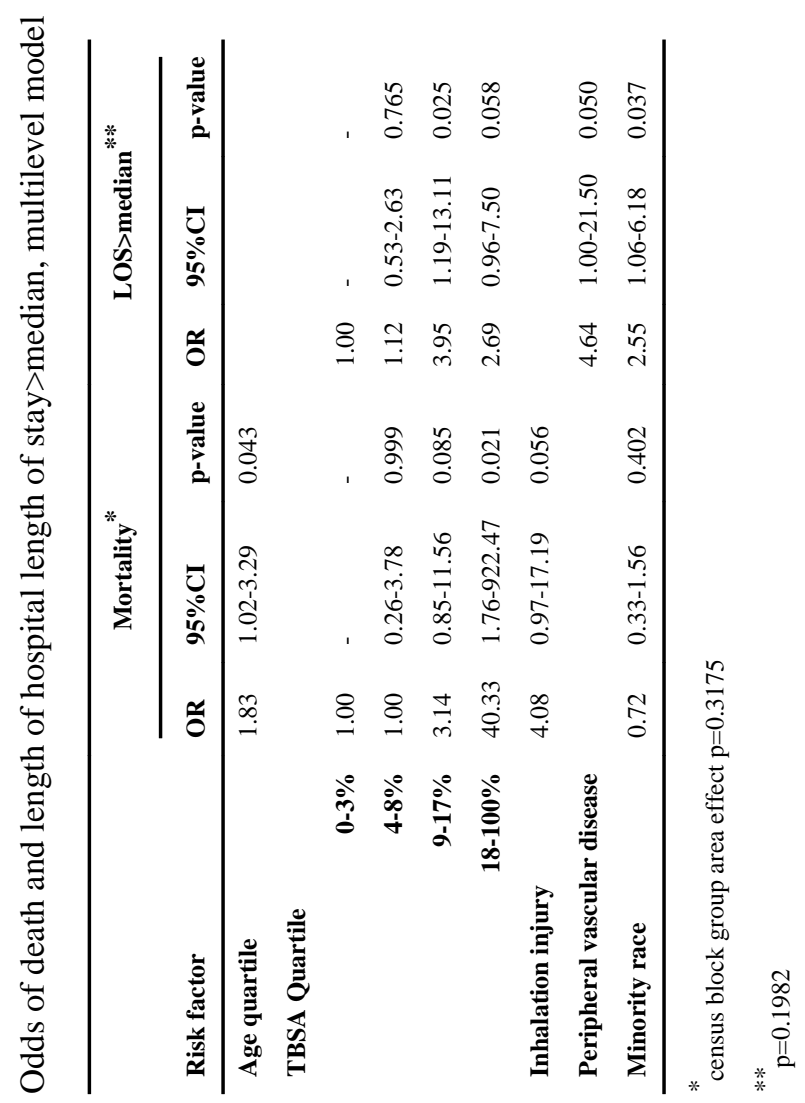

Burns. Author manuscript; available in PMC 2012 August 1. 